\title{
Perbaikan Teknik Pembrongsongan melalui Aplikasi Pestisida untuk Meningkatkan Kemulusan Buah Jambu Kristal (Psidium guajava L)
}

\section{Improving the Bagging Technique with Pesticide Application to Increase Fruit Smoothness of 'Kristal' Guava (Psidium guajava L)}

\author{
Yosephine Sista Parameswara dan Slamet Susanto*
}

Departemen Agronomi dan Hortikultura, Fakultas Pertanian, Institut Pertanian Bogor (Bogor Agricultural University), Jl. Meranti, Kampus IPB Darmaga, Bogor 16680, Indonesia

Telp.\& Faks.62-251-8629353 e-mail agrohort@apps.ipb.ac.id

*Penulis Korespondensi : slmtsanto@gmail.com

Disetujui : 21 Mei 2018 / Published Online 2 Januari 2019

\begin{abstract}
'Kristal' guava is a superior cultivar of Psidium guajava L. and has a good market in Indonesia. 'Kristal' guava has a sweet taste, crispy texture, and has a lot of nutrient. Quality is the main problem of 'kristal' guava cultivation, one of the problem is fruit appearance defects. This research aims to determine the effect of active materials of pesticides used in fruit bagging techniques on fruit smoothness. The research was conducted at Cikabayan Experimental Field and Postharvest Laboratory, Department of Agronomy and Horticulture, Bogor Agricultural University from February 2017 until August 2017. The materials used in this research consist of 4 active materials pesticide: Control, Chlorpyrifos, Abamectin, and Mankozeb. The results of this research indicated that the treatment of active materials of pesticides has a significant effect on the variables of fruit appearance defect. The treatment of active materials of pesticides improved up to double the fruit smoothness. The treatment of active materials pesticide did not have a significant effect on the diameters, softness, weight, TSS, and TTA variables.
\end{abstract}

Keywords: fruit defects, total soluble solids, total titratable acid, fruit quality, fruit bagging

\begin{abstract}
ABSTRAK
Jambu 'kristal' merupakan kultivar unggulan jambu biji dan memiliki pasar yang baik di Indonesia. Jambu kristal memiliki rasa yang manis, tekstur renyah, vitamin $C$, dan kandungan lain yang bermanfaat. Kualitas merupakan masalah utama dalam budidaya jambu 'kristal', salah satunya adalah tingkat kemulusan buah. Penelitian ini bertujuan mengetahui pengaruh bahan aktif pestisida yang digunakan pada teknik pembrongsongan buah terhadap tingkat kemulusan buah. Penelitian dilaksanakan di Kebun Percobaan Cikabayan dan Laboratorium Pascapanen, Departemen Agronomi dan Hortikultura, Institut Pertanian Bogor pada Bulan Februari 2017 hingga Agustus 2017. Bahan yang digunakan pada teknik pembrongsongan adalah bahan aktif pestisida: Klorpirifos, Abamektin, dan Mankozeb. Hasil penelitian menunjukkan bahwa perlakuan bahan aktif pestisida memberikan pengaruh yang sangat nyata pada peubah kemulusan buah. Perlakuan bahan aktif pestisida meningkatkan kemulusan buah hingga dua kali lipat. Perlakuan bahan aktif pestisida tidak memberikan pengaruh nyata pada peubah diameter, kelunakan, bobot, PTT, dan ATT.
\end{abstract}

Kata kunci: kecacatan buah, padatan terlarut total, total asam tertitrasi, mutu buah, pembrongsongan buah 


\section{PENDAHULUAN}

Jambu biji (Psidium guajava) merupakan salah satu komoditas hortikultura Indonesia dengan permintaan pasar yang tinggi. Menurut Basisdata Konsumsi Pangan Kementerian Pertanian Indonesia (2017), konsumsi buah jambu biji pada tahun 2014 sebesar $0.313 \mathrm{~kg}$ per kapita dalam rumah tangga per tahun. Indonesia termasuk dalam 10 negara penghasil utama buah jambu biji di dunia (Asia Farming, 2017). Produksi buah jambu biji di Indonesia mencapai 187.406 ton pada tahun 2014 (Ditjen Horti, 2017). Indonesia memiliki beberapa kultivar jambu biji di antaranya getas merah, mutiara, pear, dan kristal. Jambu biji kultivar kristal merupakan salah satu kultivar unggulan komoditas jambu biji di Indonesia. Jambu 'Kristal' merupakan mutasi dari jambu Muangthai Pak yang diperkenalkan di Indonesia oleh Misi Teknik Taiwan dan diintroduksi pada tahun 2001 di Mojokerto (Ditbenih, 2007). Buah ini memiliki keistimewaan antara lain jumlah biji yang kurang dari 3\% dan tekstur buah yang renyah (Kurniawan, 2015).

Jambu 'Kristal' harus memiliki mutu yang tinggi agar dapat memenuhi standar pasar dalam negeri maupun pasar internasional dan dapat diterima secara luas oleh konsumen (BSN, 2009). Definisi mutu pada produk hortikultura segar adalah kumpulan dari karakteristik dan atribut yang memberikan nilai pada produk tersebut. Penampakan masih menjadi komponen penting dalam perdagangan produk hortikultura. Namun demikian, ada peningkatan persepsi masyarakat terhadap komponen mutu yang tidak terlihat. Menurut Kader (2002), komponen mutu pada produk hortikultura dapat dievaluasi dari penampilan, tekstur, rasa, dan nilai nutrisi.

Penampilan buah merupakan komponen mutu yang pertama kali dilihat oleh konsumen. Permasalahan penampilan yang sering ditemukan dalam pasar jambu 'Kristal' adalah kemulusan buah jambu 'Kristal'. Permasalahan ini pada umumnya disebabkan oleh serangan hama, penyakit, dan cendawan pada proses budidaya. Menurut Faridah (2011) dan Eriza (2015), hama dominan yang menyerang buah jambu 'Kristal' penyebab kemulusan rendah adalah ordo lepidoptera pada fase larva dan tungau (Acarina: Tetranychidae dan Mycobatidae). Larva memakan buah pada bagian permukaan dengan cara meraut/menggerek yang akan menimbulkan bekas berwarna kecokelatan sampai buah matang. Tungau menyerang buah jambu 'Kristal' dengan cara menusuk- menghisap, bekas serangan hama tungau akan mengering, membentuk cekungan, dan berwarna kecokelatan pada permukaan buah yang akan terus membekas sampai buah matang. Selain hama, cendawan Pestalotiopsis spp juga merupakan vektor penyebab kemulusan buah jambu 'Kristal' rendah (Keith et al., 2006).

Upaya peningkatan kemulusan buah jambu 'Kristal' yang saat ini telah dilakukan adalah dengan menerapkan phytosanitary pada kegiatan budidaya, antara lain dengan penyemprotan pestisida, pembuatan perangkap hama, dan pembrongsongan (Blick et al., 2011). Penelitian ini perlu dilakukan sebagai pengembangan penerapan phytosanitary, yaitu dengan melakukan perbaikan teknik pembrongsongan untuk meningkatkan kemulusan buah jambu 'Kristal' melalui aplikasi pestisida.

\section{BAHAN DAN METODE}

Penelitian ini dilaksanakan di Kebun Percobaan Cikabayan dan Laboratorium Pascapanen Departemen Agronomi dan Hortikultura, Institut Pertanian Bogor pada bulan Februari 2017 sampai Agustus 2017. Bahan yang digunakan dalam penelitian ini adalah buah jambu biji varietas kristal, plastik pembrongsong, label, dua insektisida (klorpirifos konsentrasi $3 \mathrm{ml} / \mathrm{l}$ ), akarisida (bahan aktif: abamectin konsentrasi 0,09 $\mathrm{ml} / \mathrm{l}$ ), satu fungisida (mankozeb konsentrasi 1,6 $\mathrm{g} / \mathrm{l}$ ), indikator phenolphthalein (PP), $\mathrm{NaOH}$, dan kertas saring. Konsentrasi pestisida yang digunakan dalam penelitian ini mengacu pada anjuran dan batas aman menurut Kementerian Pertanian Republik Indonesia. Alat-alat yang digunakan pada penelitian ini adalah gunting stek, jangka sorong, ember, timbangan analitik, hand refractometer, penetrometer, alat titrasi, kamera digital, mortar, cawan petri, labu takar, labu erlenmeyer, dan alat-alat penunjang penelitian lainnya. Penelitian ini menggunakan Rancangan Percoban Faktorial satu faktor dengan menggunakan Rancangan Acak Lengkap (RAL). Faktor pada penelitian ini adalah perlakuan pestisida dengan empat taraf, yaitu bahan aktif: klorpirifos, abamectin, mankozeb, dan kontrol. Setiap perlakuan diulang sebanyak 10 kali, sehingga terdapat 40 satuan percobaan. Setiap satu satuan percobaan terdapat 5 buah. Sehingga buah yang diamati sebanyak 200 buah.

Pembrongsongan dilakukan pada bakal buah jambu kristal yang sudah berukuran $1.7 \mathrm{~cm}-$ $2 \mathrm{~cm}$ (berumur $\pm 4 \mathrm{MSA}$ ). Bakal buah yang dibrongsong adalah bakal buah yang memiliki tingkat kemulusan $100 \%$. Pembrongsongan dilakukan dengan menggunakan plastik pembrongsong yang mengandung bahan aktif pestisida (klorpirifos, abamectin, mankozeb, 
kontrol). Pemberian pestisida pada plastik pembrongsongbdilakukan dengan cara merendam plastik pembrongsong pada larutan pestisida sesuai dengan perlakuan penelitian, kemudian dikeringkan dan diaplikasikan pada teknik pembrongsongan.

Pemeliharaan kebun yang dilakukan antara lain pemupukan, sanitasi lahan, sanitasi piringan, pemangkasan, dan penjarangan buah. Pemupukan dilakukan sekali menggunakan pupuk SP-36 dan pupuk NPK mutiara. Sanitasi lahan dilakukan 2 kali, yaitu pada bulan Februari 2017 dan Juni 2017. Sanitasi piringan dilakukan satu kali, yaitu pada bulan Mei 2017. Pemangkasan dilakukan sekali pada Bulan Maret 2017. Pemangkasan dilakukan pada batang yang sudah tua, tidak produktif, dan terserang penyakit. Selain itu pemangkasan juga dilakukan pada tunas-tunas air. Pemangkasan dilakukan agar cahaya mataari diterima secara optimal oleh tanaman jambu kristal, serta pemangkasan bertujuan untuk merangsang pembungaan. Penjarangan buah dilakukan selama proses penelitian. Penjarangan buah dilakukan dengan cara membuang buahbuah yang busuk dan terserang hama penyakit.

Pengamatan lapang dilakukan setiap minggu mulai dari bakal buah dibrongsong (0 MSP) hingga panen (10 MSP). Pengamatan lapang meliputi pengamatan diameter vertikal buah menggunakan jangka sorong dan pengamatan kecacatan buah secara visual. Pengamatan pasca panen meliputi mutu fisik dan mutu kimia buah jambu kristal. Mutu fisik, yaitu persentase kecacatan buah, persentase luka bercak cokelat, jumlah luka tusuk, diameter vertikal dan diameter horizontal menggunakan jangka sorong, dan bobot buah menggunakan timbangan analitik. Sedangakan mutu kimia meliputi kelunakan yang diukur dengan alat penetrometer, Padatan Terlarut Total (PTT) yang yang diukur dengan alat refraktometer, dan Total Asam Tertitrasi yang diukur dengan melakukan titrasi $\mathrm{NaOH} 0.1 \mathrm{M}$.

\section{HASIL DAN PEMBAHASAN}

\section{Kondisi Umum}

Percobaan dilakukan di kebun Percobaan Cikabayan, Institut Pertanian Bogor. Kebun percobaan Cikabayan memiliki ketinggian $180 \mathrm{~m}$ dpl dengan jenis tanah ultisol. Suhu rata-rata selama penelitian pada bulan Februari 2017 sampai Juli 2017 di wilayah Dramaga, Bogor berkisar antara 25 sampai $26.4{ }^{\circ} \mathrm{C}$ dengan curah hujan rata-rata berkisar antara 284 sampai 526 mm (BMKG Dramaga, 2017). Pembrongsongan bakal buah jambu 'Kristal' dilakukan saat bakal buah berukuran $1.7 \mathrm{~cm}-2 \mathrm{~cm}$, berumur \pm 4 MSA (Minggu Setelah Anthesis). Proses pembrongsongan bakal buah dilakukan pada bulan Februari 2017 hingga Mei 2017. Proses pemanenan buah jambu 'Kristal' dilakukan pada bulan Mei 2017 hingga Agustus 2017. Buah jambu 'Kristal' dipanen pada umur 14 MSA. Pengamatan pascapanen dilakukan di Laboratorium Pascapanen Departemen Agronomi dan Hortikultura, Institut Pertanian Bogor sesaat setelah buah dipanen.

\section{Rekapitulasi Sidik Ragam}

Analisis ragam diperlukan untuk mengetahui pengaruh perlakuan terhadap peubahpeubah yang diamati pada penelitian. Berdasarkan hasil rekapitulasi sidik ragam (Tabel 1), peubah kecacatan buah, burik, dan luka tusuk memiliki pengaruh sangat nyata terhadap perlakuan. Peubah diameter vertikal, diameter horizontal, kelunakan, PTT, TAT, dan bobot tidak berpengaruh nyata terhadap perlakuan.

Tabel 1. Hasil rekapitulasi nilai tengah peubah pengamatan pengaruh perlakuan beberapa bahan aktif pestisida terhadap mutu buah jambu 'Kristal'

\begin{tabular}{lcrr}
\hline Peubah & Nilai Tengah & Pr>F & KK (\%) \\
\hline Diameter Vertikal (cm) & 5.28 & 0.37 tn & 8.41 \\
Diameter Horizontal (cm) & 6.93 & $0.68 \mathrm{tn}$ & 7.18 \\
Kecacatan Buah (\%) & 9.22 & $<0.0001^{* *}$ & 14.9 \\
Burik (\%) & 7.92 & $<0.0001^{* *}$ & 13.60 \\
Luka Tusuk (tusuk) & 2.80 & $<0.0001^{* *}$ & 6.37 \\
Kelunakan & 27.04 & $0.19 \mathrm{tn}$ & 13.61 \\
PTT ( ${ }^{\circ}$ brix) & 8.56 & $0.91 \mathrm{tn}$ & 16.52 \\
TAT (TAT) & 0.204 & $0.95 \mathrm{tn}$ & 11.12 \\
Bobot (g) & 144.98 & $0.83 \mathrm{tn}$ & 19.55 \\
\hline
\end{tabular}

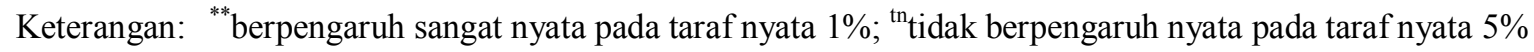




\section{Kemulusan Buah}

Berdasarkan data yang diperoleh (Gambar 1) perkembangan kecacatan buah paling cepat dialami pada kontrol, sedangkan pada perlakuan bahan aktif pestisida klorpirifos, abamektin, dan mankozeb perkembangan kecacatan buah lebih lambat dibandingkan kontrol dan cenderung sama antar perlakuan.

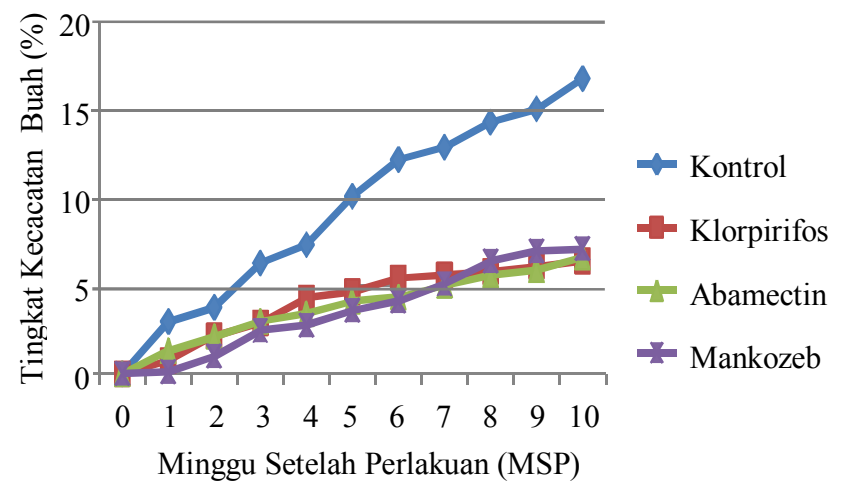

Gambar 1. Perkembangan kecacatan buah jambu 'Kristal' perlakuan pembrongsongan dengan beberapa bahan aktif pestisida

Perlakuan pembrongsongan dengan bahan aktif pestisida memberikan pengaruh yang sangat nyata terhadap persentase kemulusan buah (Tabel 2). Nilai kemulusan buah terendah terdapat pada perlakuan kontrol, yaitu $83.25 \%$. Ketiga perlakuan bahan aktif pestisida memiliki nilai kemulusan yang cenderung sama, yaitu berkisar antara $92.90 \%$ sampai $93.60 \%$.

Tabel 2 menunjukkan bahwa pemberian bahan aktif pestisida pada plastik pembrongsong meningkatkan persentase kemulusan buah. Hal ini diduga karena bahan aktif pestisida yang digunakan dalam penelitian sudah sesuai dengan OPT (Organisme Pengganggu Tanaman) sasaran, sehingga menjadi pelindung tambahan pada plastik pembrongsong buah. Menurut Faridah (2011) dan Eriza (2015), hama dominan yang

Tabel 2. Pengaruh perlakuan beberapa bahan aktif pestisida terhadap persentase kemulusan buah

\begin{tabular}{lcc}
\hline $\begin{array}{l}\text { Bahan } \\
\text { Aktif }\end{array}$ & $\begin{array}{c}\text { Kecacatan } \\
\text { Buah (\%) }\end{array}$ & $\begin{array}{c}\text { Kemulusan Buah (\%) } \\
(100 \%-\text { Kecacatan } \\
\text { Buah) }\end{array}$ \\
\hline Kontrol & $16.75 \mathrm{a}$ & $83.25 \mathrm{a}$ \\
Klorpirifos & $7.10 \mathrm{~b}$ & $92.90 \mathrm{~b}$ \\
Abamektin & $6.62 \mathrm{~b}$ & $93.38 \mathrm{~b}$ \\
Mankozeb & $6.4 \mathrm{~b}$ & $93.60 \mathrm{~b}$ \\
\hline
\end{tabular}

Keterangan: Angka-angka yang diikuti oleh huruf yang berbeda pada kolom yang sama menunjukkan berbeda nyata menurut Uji DMRT pada taraf $\alpha=5 \%$. menyerang buah jambu 'Kristal' penyebab rendahnya kemulusan permukaan buah adalah ordo lepidoptera pada fase larva dan tungau (Acarina: Tetranychidae dan Mycobatidae). Jamur penyebab rendahnya kemulusan permukaan buah yaitu Pestalotiopsis spp (Keith et al., 2006).

Berdasarkan pengamatan pada penelitian, rendahnya kemulusan buah pada umumnya disebabkan oleh dua tipe kecacatan, yaitu burik dan luka tusuk. Perlakuan bahan aktif pestisida berpengaruh sangat nyata terhadap persentase burik dan luka tusuk pada buah jambu 'Kristal' (Tabel 3). Persentase burik tertinggi pada perlakuan kontrol, yaitu sebesar $15.12 \%$. Luka burik pada perlakuan ketiga bahan aktif pestisida memiliki nilai yang tidak berbeda nyata, yaitu berkisar antara $4.76 \%$ sampai $6.19 \%$. Jumlah luka tusuk perlakuan kontrol berbeda nyata dengan jumlah luka tusuk ketiga perlakuan bahan aktif pestisida (Tabel 3). Jumlah luka tusuk terbanyak terdapat pada buah jambu 'Kristal' dengan perlakuan kontrol, yaitu 4.88. Jumlah luka tusuk pada ketiga bahan aktif pestisida tidak berbeda nyata, yaitu berkisar antara 1.96 sampai 2.18.

Tabel 3. Pengaruh perlakuan beberapa bahan aktif pestisida terhadap burik dan luka tusuk

\begin{tabular}{lcc}
\hline $\begin{array}{l}\text { Bahan } \\
\text { Aktif }\end{array}$ & Burik (\%) & Luka Tusuk (\%) \\
\hline Kontrol & $15.12 \mathrm{a}$ & $4.88 \mathrm{a}$ \\
Klorpirifos & $4.76 \mathrm{~b}$ & $2.15 \mathrm{~b}$ \\
Abamektin & $6.19 \mathrm{~b}$ & $1.96 \mathrm{~b}$ \\
Mankozeb & $5.59 \mathrm{~b}$ & $2.18 \mathrm{~b}$
\end{tabular}

Keterangan: Angka-angka yang diikuti oleh huruf yang berbeda pada kolom yang sama menunjukkan berbeda nyata menurut Uji DMRT pada taraf $\alpha=5 \%$.

\section{Diamater Buah}

Buah jambu 'Kristal' dipanen 10 minggu setelah perlakuan pembrongsongan, berumur 14 MSA ( \pm 104 hari). Berdasarkan hasil pengamatan (Gambar 2) menunjukkan bahwa tidak nampak perbedaan antar fase pada perkembangan buah jambu 'Kristal'. Umumnya, perkembangan buah terdiri dari 3 fase, yaitu fase 1 pembelahan sel, fase 2 pembesaran sel, dan fase 3 pematangan. Menurut Iglesias et al. (2007), pada fase 1 laju pertumbuhan diameter masih lambat, fase 2 pertumbuhan diameter lebih cepat dibandingkan minggu-minggu sebelumnya atau sesudahnya, dan pada fase 3 pertumbuhan diameter buah mengalami perlambatan dan cenderung konstan. 


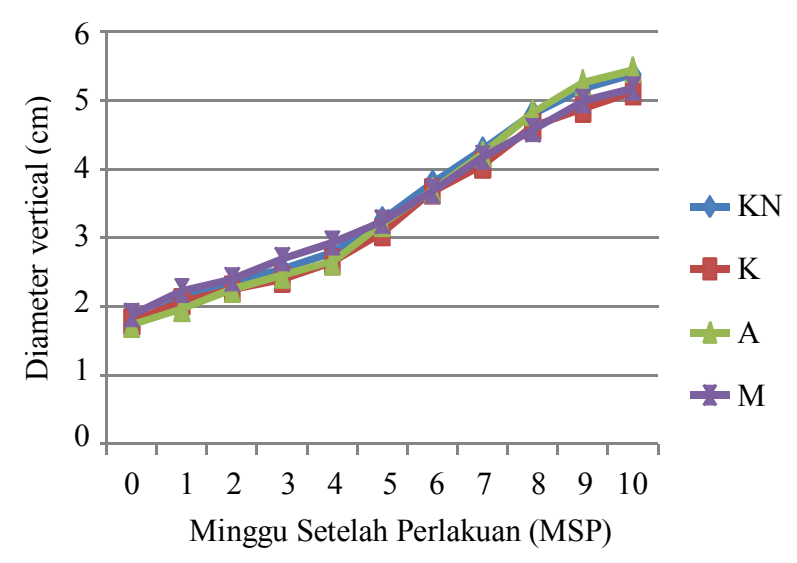

Gambar 2. Perkembangan diameter vertikal buah jambu 'Kristal' perlakuan pembrongsongan dengan beberapa bahan aktif pestisida; $\mathrm{KN}=$ Kontrol; K = Klorpirifos; A = Abamektin; $\mathrm{M}$ $=$ Mankozeb

Hasil penelitian (Tabel 4) menunjukkan perlakuan bahan aktif pestisida tidak berpengaruh nyata terhadap diameter horizontal dan diameter vertikal. Nilai diameter vertikal pada semua perlakuan cenderung sama, yaitu berkisar antara $5.12 \mathrm{~cm}$ sampai $5.45 \mathrm{~cm}$. Nilai diameter horizontal pada semua perlakuan cenderung sama, yaitu berkisar antara $6.82 \mathrm{~cm}$ sampai $7.07 \mathrm{~cm}$. Nilai ini lebih kecil dibandingkan penelitian yang dilakukan oleh Fitria (2016), yaitu berkisar antara $8.1 \mathrm{~cm}$ sampai $8.4 \mathrm{~cm}$. Hal ini diduga karena tanaman mengalami kekurangan air selama proses perkembangan buah.

Tabel 4. Pengaruh perlakuan beberapa bahan aktif pestisida terhadap diameter horizontal dan diameter vertikal buah

\begin{tabular}{lcc}
\hline Bahan Aktif & $\begin{array}{c}\text { Diameter } \\
\text { Vertikal }(\mathrm{cm})\end{array}$ & $\begin{array}{c}\text { Diameter } \\
\text { Horizontal }(\mathrm{cm})\end{array}$ \\
\hline Kontrol & 5.38 & 7.07 \\
Klorpirifos & 5.12 & 6.85 \\
Abamektin & 5.45 & 6.98 \\
Mankozeb & 5.17 & 6.82 \\
\hline
\end{tabular}

\section{Mutu Kimia}

Berdasarkan data yang diperoleh (Tabel 5) perlakuan bahan aktif pestisida tidak berpengaruh nyata pada semua peubah mutu kimia buah yang diamati, yaitu kelunakan, bobot, TAT, dan PTT. Hasil penelitian (Tabel 5) menunjukkan perlakuan bahan aktif pestisida tidak berepengaruh nyata terhadap tingkat kelunakan. Nilai kelunakan pada setiap perlakuan cenderung sama, yaitu berkisar antara $25.48 \mathrm{~mm} / 152 \mathrm{~g} / 5 \mathrm{~s}$ hingga $28.88 \mathrm{~mm} / 152$ $\mathrm{g} / 5 \mathrm{~s}$. Hal ini diduga karena tingkat kelunakan buah bergantung pada metabolisme buah, bukan dari faktor eksternal buah. Tingkat kelunakan buah jambu 'Kristal' akan bertambah seiring dengan proses pemasakan buah (Widodo et al, 2013). Menurut Syafutri et al., (2006) kelunakan buah terjadi karena adanya perubahan pektin yang tidak dapat larut (protopektin) menjadi pektin yang dapat larut saat proses pemasakan buah.

Perlakuan bahan aktif pestisida tidak berpengaruh nyata terhadap bobot buah jambu 'Kristal' (Tabel 5). Nilai bobot buah jambu 'Kristal' pada semua perlakuan cenderung sama, yaitu berkisar antara $140.05 \mathrm{~g}$ sampai $150.47 \mathrm{~g}$. Menurut Fitria (2016), bobot buah terkait dengan jumlah asimilat yang dihasilkan dan ditaranslokasikan dari source ke sink.

Tabel 5. Pengaruh perlakuan beberapa bahan aktif pestisida terhadap diameter horizontal dan diameter vertikal buah

\begin{tabular}{lcc}
\hline Bahan Aktif & $\begin{array}{c}\text { Kelunakan } \\
(\mathrm{mm} / 50 \mathrm{~g} / 5 \mathrm{~s})\end{array}$ & Bobot (gram) \\
\hline Kontrol & 27.80 & 148.11 \\
Klorpirifos & 26.00 & 140.05 \\
Abamektin & 28.88 & 150.47 \\
Mankozeb & 25.48 & 141.30 \\
\hline
\end{tabular}

Hasil penelitian menunjukkan bahwa perlakuan pembrongsongan dengan menggunakan bahan aktif pestisida tidak berpengaruh nyata terhadap peubah PTT dan ATT yang diamati. Berdasarkan hasil penelitian nilai PTT berkisar antara $8.40^{\circ}$ brix hingga $8.68{ }^{\circ}$ brix (Tabel 6). Nilai ATT yang diperoleh berkisar antara $0.201 \%$ hingga $0.207 \%$. Berdasarkan data yang diperoleh, rasio PTT/ATT berkisar antara 40.97 sampai 43.18. Rasio PTT/ATT merupakan hal penting yang dapat dijadikan indikator kesukaan konsumen.

Tabel 6. Pengaruh perlakuan beberapa bahan aktif pestisida terhadap PTT dan ATT buah

\begin{tabular}{lccc}
\hline Bahan Aktif & PTT ( ${ }^{\circ}$ brix) & ATT (\%) & PTT/ATT \\
\hline Kontrol & 8.40 & 0.205 & 40.97 \\
Klorpirifos & 8.64 & 0.207 & 41.74 \\
Abamektin & 8.68 & 0.201 & 43.18 \\
Mankozeb & 8.50 & 0.204 & 41.67 \\
\hline
\end{tabular}

\section{KESIMPULAN}

Hasil penelitian ini menunjukkan bahwa perlakuan bahan aktif pestisida klorpirifos, abamektin, dam mankozeb memberikan pengaruh sangat nyata menurunkan tingkat kecacatan buah jambu 'Kristal' (Psidium guajava L). Perlakuan bahan aktif pestisida menurunkan kecacatan buah hingga dua kali lipat. Perlakuan bahan aktif pestisida kloripirifos, abamektin, dan mankozeb tidak berpengaruh nyata terhadap peubah diameter, PTT, ATT, kelunakan, dan bobot buah. 


\section{DAFTAR PUSTAKA}

Abbasi, N.A., M.A. Chaudhary, M.I. Ali, A. Hussain, I. Ali. 2014. On tree fruit bagging influences quality of guava harvested at different maturity stages during summer. Int. J. Agric. Biol. :53-59.

Alok, R.N., D.D. Chatterjee, T. Roy, A.M.M.Z. Hossain, M.A. Haque. 2011. Study on chemical changes of different guava varieties during different ripening stage. Bangladesh Res. Pub. J. 6(2): 217- 224.

Amarante, C., N.H. Banks, S. Max. 2002. Preharvest bagging improves packout and fruit quality of pears (Pyrus communis). New Zealand Journal of Crop and Horticultural Science. 30:93-98.

Ashari, S. 2006. Hortikultura: Aspek Budidaya. Edisi revisi. UI Press, Jakarta.

Asia Farming. 2018. Guava cultvation information guide. http://www.asiafarming. com/guava- cultivation/. [10Januari 2018]

Azzamy. 2015. Jenis-jenis pestisida berdasarkan mekanisme kerjanya. http://mitalom.com. [13 November 2017]

[Balitbu] Balai Penelitian Tanaman Buah Tropika. 2007. Budi daya Jambu Biji. http://hortikultura.litbang.pertanian.go.id/. [10 Desember 2017].

Bashir, A.H., A.A. Abu-Goukh. 2003. Composi tional changes during guava fruit ripening. Food Chemistry. 80:557-563.

Beckles, D.M., 2012. Factors affecting the postharvest soluble solids and sugar content of tomato (Solanum lycopersicum L.) fruit. Postharvest Biology and Technology, 63(1): 129-140.

[BKP Kementan] Basisdata Konsumsi Pangan Kementerian Pertanian. 2017. Konsumsi komoditas buah- buahan per kapita dalam rumah tangga setahun menurut hasil susenas 2014. https://aplikasi2.pertanian. go.id/konsumsi/tampil_susenas_kom2_th.p hp [22 Desember 2017]

[BMKG] Badan Meteorologi, Klimatologi, dan Geofisika. 2017. Data Klimatologi Tahun 2017. BMKG Dramaga, Bogor.

[BSN] Badan Standardisasi Nasional. 2009. Jambu biji. http://sisni.bsn.go.id. [7 November 2017]

Blick, A.P., S.R. Roberto, M.V.E. Grossmann, F. Yamashita. 2011. Efficacy of some biodegradable films as preharvest covering material for guava. Sci. Hort. 130:341-343.

Crane, J.H., C.F. Balerdi.2006. Guava growing in the florida home landscape. Horticultural Sciences Department document HS4. Institute of Food and Agricultural Sciences. University of Florida, Gainesville.

[Cybext Kementan] Cyber Extension Kementerian Pertanian. 2017. Manfaat jambu biji bagi kesehatan. http://cybex.pertanian.go.id/mate ripenyuluhan/detail/8990/manfaat-jambu-bi ji-bagi-kesehatan. [23 Desember 2017]

Dadang. 2006. Pengenalan Pestisida dan Teknik Aplikasi. Workshop Hama dan Penyakit Tanaman Jarak (Jatropa curcas Linn.): Potensi Kerusakan dan Teknik Pengendaliannya, Bogor.

[Ditbenih] Direktorat Perbenihan Hortikultura. 2007. Deskripsi jambu biji varietas Kristal. http://varitas.net/dbvarietas/deskripsi/3136. pdf. [23 Desember 2017].

[Ditjen Horti] Direktorat Jenderal Hortikultura. Statistik produksi hortikultura. http:// hortikultura.pertanian.go.id/wpcontent/uplo ads/2016/02/Statistik-Produksi-2014.pdf. [10 Januari 2018]

Eriza, A. 2015. Hama dan penyakit tanaman jambu 'Kristal' (Psidium guajava L) di Agribusiness Development Station Cikarawang Bogor. [Skripsi]. Institut Pertanian Bogor, Bogor.

Faridah, D. 2011. Hama dan penyakit tanaman jambu biji (Psidium guajava L) di Kecamatan Bogor dan Kampus IPB Dramaga Bogor. [Skripsi]. Institut Pertanian Bogor, Bogor.

Gould, W.P., A. Raga. 2002. Pest of guava. In: J.E. Pena, J.L. Sharp, M. Wysoki, (eds.). Tropical Fruit Pests and Pollinators: Biology, Economic Importance, Natural Enemies, and Control. CABI, New York. page 295-313.

Fitria, L. 2016. Kajian pertumbuhan, produksi, dan kualitas jambu biji var. Kristal pada asal bibit dan pemangkasan yang berbeda. [Tesis]. IPB, Bogor.

Harachl, S., K. Wanichkul. 2006. Influences of bagging methods on fruit quality of guava (Psidium guajava L). Kamphaengsaen Acad. J. 4 (1): 41-47.

Iglesias, D.J., M. Cercos, J.M. Colmenero-Flores, M.A. Naranjo, G. Rios, E. Carrera, O. Ruiz- 
Rivero, I. Lliso, R. Morrilon, F.R. Tadeo, M. Talon. 2007. Physology of citrus fruiting. Braz. J. Plant. Physiol. 19(4): 333362.

[Litbangtan] Badan Penelitian dan Pengembangan Pertanian. 2018. Pestisida. http://horti kultura.litbang.pertanian.go.id/Modul\%20P TT/Cabai/Pestisida.pdf. [10_Januari 2018]

Kader, A.A. 2002. Quality Parameters of FreshCut Fruit and Vegetable Products. Freshcut Fruit and Vegetable Product. O. Lamikanra, (ed.). CRC Press, Boca Raton, Florida.

Keith, L., M. Velasquez, F. Zee. 2006. Identification and characterization of Pestalotiopsis spp. causing scab disease of guava, Psidium guajava, in Hawaii. Plant Disease. 90(1): 16-23.

Khushk, A.M., A. Memon, M.I. Lashari. 2009. Factors affecting guava production in Pakistan. J. Agric.Res. Vol. 47(2).

Kurniawan, D. 2015. Mengenal jambu 'Kristal'. Direktorat Jenderal Hortikultura Kemen trian Pertanian Indonesia. http://hortikul tura.pertanian.go.id/?\%20p=354_[22 Desem ber 2017]

Kurniawati, A., Kasutjianingati, B. Miftahul. 2016. Pengaruh pembrongsongan terhadap kualitas serta tingkat serangan hama penyakit buah pisang tanduk. J. Agrotek Indonesia 1(2): 99-104.

Lim, T.K., B.C. Manicom. 2003. Diseases of guava. In: R.C. Ploetz, (ed.). 2003. Diseases of Tropical Fruit Crops. CABI Publishing: Wallingford, UK.

Metwally, A.M., A.A Omar, N.M. Ghazy, F.M. Harraz, S.M El Sohafy. 2011. Monograph of Psidium guajava L. leaves. Phcog J. 3:21

Patel, R.K., C.S. Maiti, B.C. Deka, N.A. Deshmukh, V.K. Verma, A. Nath. 2015. Physical and biochemical changes in guava (Psidium guajava L.) during various stages of fruit growth and development. IJAEB. 8(1): 75-82.

Paull, R.E., O. Duarte. 2012. Tropical Fruits Volume 2. CAB International, London.

Pratidina, R., M. Syamsun, N.H. Wijaya. 2015. Analisis pengendalian mutu jambu 'Kristal' dengan metode six sigma di ADC IPB-
ICDF Taiwan Bogor. J Manajemen dan Organisasi. VI(1):1-18.

Sivakumar, D., Y. Jiang, E.M. Yahia. 2011. Maintaining mango (Mangifera indica L.) fruit quality during the export chain. Food Research International. 44: 1254-1263.

Son, I.C., C.H. Lee. 2008. The effects of bags with different light transmittance on the berry cracking of grape "Kyoho". Hortic. Environ. Biotechnol. 49: 98-103

Suketi, K., R. Poerwanto, S. Sujiprihati, Sobir, W.D. Widodo. 2010. Karakter fisik dan kimia buah pepaya pada stadia kematangan berbeda. J Agron Indonesia. 38 (1): 60-66.

Sunpride. 2016. Jambu 'Kristal'. http://www. sunpride.co.id/product detail.html?cat=buah nusantara \&fruit= guava\&id=15\#sthash. oGILCCAV.dpbs. [19 Desember 2017].

Syafutri, M.I., F. Pratama, D. Saputra. 2006. Sifat fisik dan kimia buah mangga (Mangifera indica L.) selama penyimpanan dengan berbagai metode pengemasan. J Teknol dan Industri Pangan. 17(1):1-11.

[USDA] United State Department of Agriculture. 2016. National nutrient database for standard reference release 28 . https://ndb. nal.usda.gov/ndb/foods/show/2246?manu= $\&$ fgcd $=\& d s=$. [19 Desember 2017]

Widodo, S.E., Zulferiyenni, M. Icha. 2012. Pengaruh penambahan indole acetic acid (IAA) pada pelapisan kitosan terhadap mutu dan masa simpan buah jambu biji (Psidium guajava L.) 'Crystal'. J. Agrotropika. 17(1): 14-18

Widodo, S.E., Zulferiyenni, D.W. Kusuma. 2013. Pengaruh penambahan benziladenin pada pelapis kitosan terhdap mutu dan masa simpan buah jambu biji 'crystal'. Jurnal Agrotek Tropika 1(1):55-60.

Xu, H.X., J.W. Chen, M. Xie. 2010. Effect of different light transmittance paper bags on fruit quality and anti-oxidant capacity in loquat. Journal of the Science of Food and Agriculture. 90:1783-1788.

Zhai, H., C. Ren, E.M. Li, D.C. Shi, G.Y. Lin, X.Y. Liu. 2006. The effect of different bagging periods on the quality of red Fuji apple in Weibei dry land. J. Northwest For. Univ. 20: 188-120. 